\title{
Estudo das funções narrativas e estilísticas de sombras e sons nos filmes de influência expressionista $O$ anjo azul e $M$ - o vampiro de Düsseldorf
}

\author{
Juan Francisco Celín Robalino ${ }^{1}$ \\ Universidade Federal de Minas Gerais, Brasil
}

\begin{abstract}
In the cinematography of German Expressionism, the lighting forms dark atmospheres inhabited by sinister characters whose distorted and enlarged shadows represent their negative burden. The contrast between light and shadow is crucial in the mise-en-scène of the films "Das Cabinet des Dr. Caligari" and "Nosferatu", in which the narrative and stylistic functions of the shadow are evidenced in the composition of the scenes. Also in the transition of the so-called "silent cinema" to the sound cinema, the expressionist influence directors Josef von Sternberg and Fritz Lang, in works such as The Blue Angel and $M$ - the vampire of Düsseldorf, have conferred dramatic value on the sound elements through the use of synchronous and asynchronous sound. In these works, the sound elements contribute to the creation of frightening atmospheres that replace the shadows or that, adding to them, increase the dramatic tension of the scenes. Subsequently, this junction of the shadows and the sound elements for the purpose of creating dramatic effects will be widely explored by sound cinema, especially in the genres of suspense and terror.
\end{abstract}

Keywords: Shadow, Mise-en-scène, Expressionist Cinema, Sound Elements, Sound Cinema

\section{Introdução}

O lançamento do filme $O$ cantor de jazz (The Jazz Singer, 1927, USA), dirigido por Alan Crossland, foi marco histórico que separou o cinema mudo do sonoro, uma vez que este filme foi o primeiro longa-metragem de fiç̧ão realizado com som parcialmente sincronizado. $\mathrm{O}$ dispositivo de produção que a indústria de cinema usou nesse filme provocou grandes câmbios na produção cinematográfica mundial, visto que as equipes tiveram que se trasladar a estúdios para poder gravar o som direto da voz dos atores, também as câmeras foram colocadas em revestimentos acústicos, chamados de ice box, que limitavam sua mobilidade. Por esses motivos, os planos ficaram maiores e mais estáticos, já que, no lugar do diretor do filme, o engenheiro de som era quem decidia que tomada estava ótima e, normalmente, ele escolhia o plano no qual o movimento dos atores era menor (JULLIER, 2007, p. 11). O alcance desse fenômeno foi universal, atingindo igualmente "a produção alemã [, que] teve que sofrer [...] deficiências [como]: frontalidade de signo teatral, câmara estática, escassa mobilidade dos atores, nula profundidade de campo pelo uso de película pancromática, etc." (SÁNCHEZ-BIOSCA, 1990, p. 405).

Nesse contexto, o pesquisador espanhol SánchezBiosca distingue na grande massa de musicais, comédias e operetas produzidos no período "sonoro" do cinema de Weimar, filmes que usam de maneira inovadora o som. Tratam-se de manifestações "experimentalmente arcaizantes" que retomaram a atmosfera de terror, a temática fantástica e a dinâmica vanguardista, reinterpretando (aquilo que parecia ser impraticável com o som) o fantástico, o demoníaco, a atmosfera, o vanguardismo etc. (SÁNCHEZBIOSCA, 1990, p. 426). Entre eles O Anjo Azul (Der blaue Engel, 1930), dirigido pelo vienense radicado nos Estados Unidos Josef von Sternberg, e M - O vampiro de Düsseldorf ( $M$ - Eine Stadt sucht einen Mörder, 1931), dirigido por Fritz Lang, os quais serão analisados nesta pesquisa.

Destarte, com o objetivo de comparar as sombras e os elementos sonoros dos filmes do cinema mudo e sonoro, examinam-se brevemente as funções narrativas e estilísticas da sombra e sua carga negativa em fotogramas dos filmes $\mathrm{O}$ Gabinete do Dr. Caligari (Das Cabinet des Dr. Caligari, 1919) dirigido por Robert Wiene e Nosferatu (Nosferatu, Eine Symphonie des Grauens, 1922), dirigido por F. W. Murnau, do chamado cinema mudo. Depois, se estudam as sombras e os elementos sonoros nos filmes de influência expressionista, da transição do cinema mudo ao sonoro, $\mathrm{O}$ anjo azul (Der blaue Engel, 1930), de Josef von Sternberg, e M - o vampiro de Düsseldorf (M - Eine Stadt sucht einen Mörder, 1931), de Fritz Lang. Finalmente, se inferem analogias entre as funções das sombras e os elementos sonoros dos dois últimos filmes.

\section{As sombras expressionistas}

Como salienta a historiadora do cinema de Weimar Lotte Eisner, corroborando o que Gubern sustenta ser a referência pictórica do Expressionismo cinematográfico ${ }^{2}$, "a nostalgia do claro-escuro e das sombras, inata nos alemães", evidentemente encontra no cinema "um modo de expressão ideal" (EISNER, 2002, p. 25). Dessa forma, como salienta Bertrand Lira, "é atribuída aos filmes expressionistas uma iluminação dramática, altamente contrastada, onde a oposição claro-escuro sintetiza o embate entre forças do Bem e do Mal comum nos seus enredos" (LIRA, 2008 , p. 128). Deleuze, por sua vez, ressalta que o expressionismo "opera com as trevas e a luz, o fundo negro opaco e o princípio luminoso: as duas potências se acoplam, se abraçam como lutadores e dão ao espaço uma intensa profundidade, uma perspectiva acusada e deformada que se preencherá de sombras" ${ }^{3}$ (DELEUZE, 1984, p. 163).

No dicionário teórico e crítico do cinema encontramos a seguinte definição de Expressionismo cinematográfico: 
As diversas definições dadas ao expressionismo cinematográfico, inspiradas em definições pictóricas e teatrais, são geralmente bastante arbitrárias, porém confluem todas em alguns elementos: o tratamento da imagem como 'gravura' (forte contraste de branco e preto); os decorados muito gráficos, onde predominam os planos inclinados; o jogo 'de giros' dos atores; o tema da rebelião contra a autoridade ${ }^{4}$ (AUMONT \& MARIE, 2015, p. 88).

Influenciado pelo estilo claro-escuro, chamado de tenebroso (escuro) desenvolvido na arte pictórica pelo mestre italiano Michelangelo Merisi, conhecido como Caravaggio, (GOMBRICH, 1995, p. 393); o cinema expressionista explorará o contraste entre a luz e a sombra para destacar os elementos fílmicos de sua mise-en-scène. Podemos observar isso na última cena de Nosferatu (figura 1), a qual é iluminada por uma lâmpada localizada no lado direito do quadro cuja luz se reflete nos objetos de cor branca, como o lençol da cama, a camisola de Ellen e a cabeça do vampiro, o qual está sugando o sangue de sua vítima. Esses elementos narrativos e estilísticos ${ }^{5}$ são indícios que permitem deduzir a ação que acontece na cena sem que seja necessário assistir a todo o filme. A camisola alva de Ellen representa a pureza dessa personagem que é profanada pelo vampiro nas horas noturnas. A direção da iluminação ressalta a mão direita do vilão. Pelo contraste entre a luz e a sombra, ela se assemelha a uma garra que, junto com a cabeça, emerge das trevas. Mimetizado por causa da tonalidade escura das vestes, o corpo do vampiro parece fazer parte dessa escuridão. Por conseguinte, tem-se a impressão de que o ente maldito nasce da sombra que, como formula o pesquisador do demoníaco na arte Enrico Castelli, "a sombra oculta o monstro" (CASTELLI, 2007, p. 155).

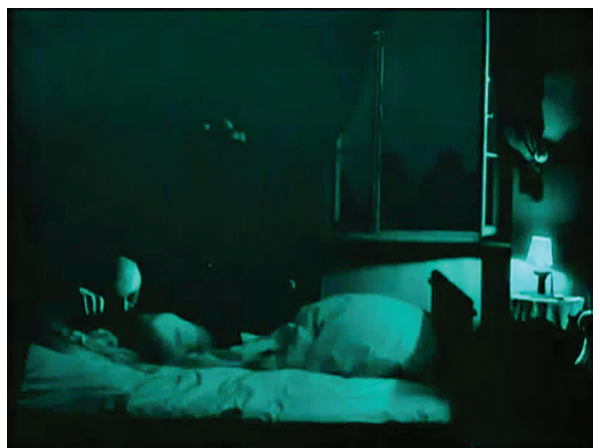

Figura 1 - Fotograma do filme Nosferatu, uma sinfonia do horror (Nosferatu, Eine Symphonie des Grauens), 1922, Dir. F. W. Murnau. Fonte: Filme Nosferatu, uma sinfonia do horror (Nosferatu, eine Symphonie des Grauens), 1922, Dir. F. W. Murnau.

Das sombras do cinema expressionista "saem o mago, o tirano, o assassino, o demônio, o vampiro - seres proscritos pelo Bem, obrigados a viver na clandestinidade, nas trevas, num sonho intermitente" (NAZARIO, 1999, p. 165). Uma vez que esses personagens brotam da escuridão, que é "uma reserva, um lugar próprio do pictórico, sobre o qual podem se alçar, ou do qual podem provir as figuras" (AUMONT, 2014, p. 91). Assim como no filme O Gabinete do doutor Caligari, o sonâmbulo Cesare emerge das trevas como uma sombra estilizada para cometer um crime (Figura 2). Diante da plasticidade desse plano, "temos a sensação de ver uma poça preta, um corpo que é puro derrame de preto, que carrega consigo a noite que o circunda e também a pintura do cenário"6 (AUMONT, 2014, p. 92).

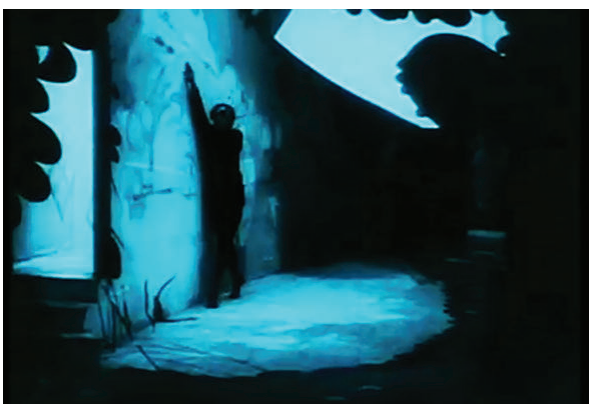

Figura 2 - Fotograma do filme O Gabinete do Dr. Caligari (Das Kabinett des Dr. Caligari, 1919) dirigido por Robert Wiene. Fonte: Filme O Gabinete do Dr. Caligari (Das Kabinett des Dr. Caligari, 1919) dirigido por Robert Wiene.

Como podemos ver nesse fotograma (figura 2), tanto o enquadramento como o contraste entre a luz e a sombra criam a impressão de profundidade de campo. No terceiro plano da perspectiva, vemos a "fossa preta" da qual emergiu o sonâmbulo (que veste um figurino preto). No segundo plano, Cesare realiza um movimento estilizado encostado numa parede pintada de branco com contornos pretos. No primeiro plano vemos o umbral pelo qual ingressará. Dessa forma o contraste entre a luz e a sombra, e a estilização do cenário e do personagem, localizam e integram os elementos fílmicos dentro da mise-enscène expressionista. Nesse movimento de vanguarda

as formas estão distorcidas e exageradas, de forma pouco realista, com fins expressivos. Os atores levam frequentemente muita maquiagem e se movem de forma espasmódica ou lenta e sinuosa. E o que é mais importante, todos estes elementos da miseen-scène interagem graficamente para criar uma composição global. Os personagens não existem simplesmente dentro de um cenário, senão que, ao contrário, formam elementos visuais no interior do cenário $^{7}$ (BORDWELL \& THOMPSON, 1993, p. 461)

Seguindo uma proposta estética similar, no filme Nosferatu o vampiro emerge de um túnel coberto de trevas para receber a visita do corretor de imóveis Hutter. Assim, a iluminação arranca, do fundo da obscuridade, o vampiro (figura 3), dando a impressão de que Nosferatu, como um animal noturno, emerge duma caverna coberta de trevas. Essa opção contribui para a narrativa, porque, conforme Pastoureau: 
"todos os locais escuros e matriciais [...] são locais de sofrimento e infelicidade, habitados por monstros [...] a obscuridade faz da caverna uma prisão, um lugar de punição e tortura, um sepulcro ou um verdadeiro inferno" (PASTOUREAU, 2011, p. 20).

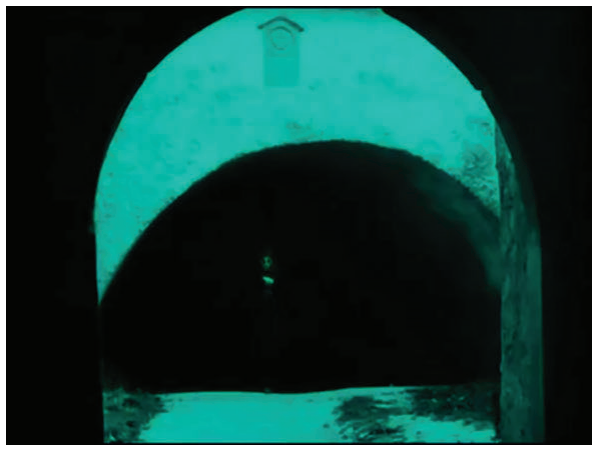

Figura 3 - Fotograma do filme Nosferatu (Nosferatu, Eine Symphonie des Grauens, 1922), dirigido por F. W. Murnau. Fonte: Filme Nosferatu (Nosferatu, Eine Symphonie des Grauens, 1922), dirigido por F. W. Murnau

Nosferatu, vestido de preto, caminha de maneira estilizada até se posicionar na área central do enquadramento. Hutter, o corretor de imóveis, atravessa outro umbral até se encontrar com o vampiro. A composição desse plano dá destaque, no canto superior direito, a uma sombria forma circular que tem um fino contorno luminoso (Figura 4). O uso desse tipo de elementos fílmicos no lugar dos catches pretos é recorrente na mise-en-scène das sequências do castelo.

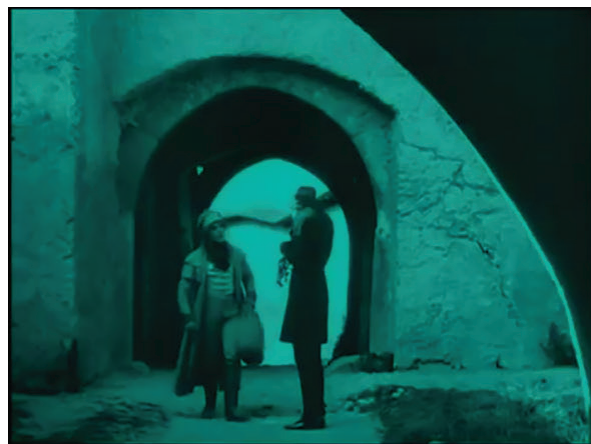

Figura 4 - Fotograma do filme Nosferatu (Nosferatu, Eine Symphonie des Grauens, 1922), dirigido por F. W. Murnau. Fonte: Filme Nosferatu (Nosferatu, Eine Symphonie des Grauens, 1922), dirigido por F. W. Murnau.

Hutter segue Nosferatu pelo interior do túnel (figura 5), naquele fundo preto, até se dissolver na cor das trevas e da noite, na cor das entranhas da terra, do mundo subterrâneo e também da morte (PASTOUREAU, 2011, p. 28).

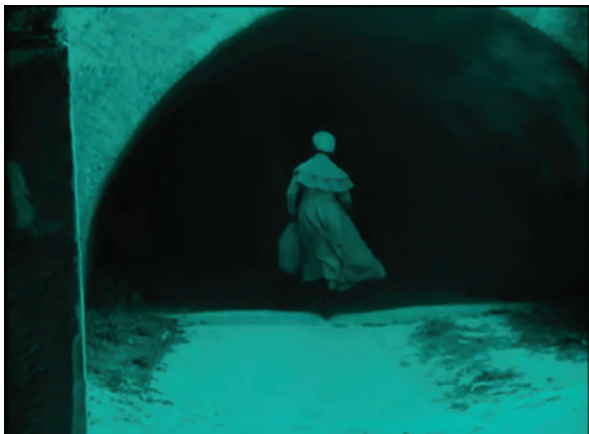

Figura 5 - Fotograma do filme Nosferatu (Nosferatu, Eine Symphonie des Grauens, 1922), dirigido por F. W. Murnau. Fonte: Filme Nosferatu (Nosferatu, Eine Symphonie des Grauens, 1922), dirigido por F. W. Murnau.

A sombra substitui o corpo que a projeta, como no fotograma (figura 6) do Gabinete do Doutor Caligari, no qual vemos silhuetas ocupando o lugar dos personagens na cena em que o inconsciente Cesare mata sua vítima. Isso confirma que, no cinema, como aponta Jacques Aumont (AUMONT, 2014, p. 290), "a sombra dos seres pode transformar-se em personagem [...] quase sempre no registro do fantástico ou a projeção psíquica (a sombra dos assassinos) ${ }^{8}$ ". As sombras substituem os atores que se encontram fora do campo e, por conseguinte, nos permitem imaginar aquilo que não podemos ver na tela.

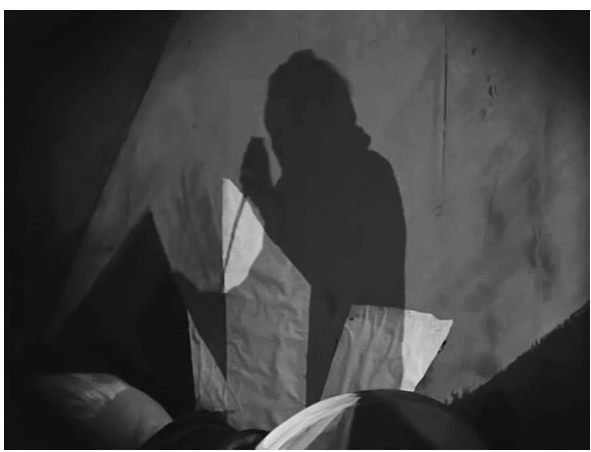

Figura 6 - Fotograma do filme O Gabinete do Dr. Caligari (Das Kabinett des Dr. Caligari, 1919), dirigido por Robert Wiene. Fonte: Filme O Gabinete do Dr. Caligari (Das Kabinett des Dr. Caligari, 1919), dirigido por Robert Wiene

A mise-en-scène do cinema expressionista deforma e aumenta as sombras dos personagens para realçar sua maldade interior, como se pode observar num plano, no qual o Dr. Caligari projeta uma silhueta sinistra (figura 7), que destaca o influxo demoníaco desse personagem sobre suas vítimas. Jacques Aumont aponta que o cinema expressionista explorou a relação simbólica entre escuridão e malefício, lembrando que Lotte Eisner inventou o epíteto "demoníaco" para destacar o amor germânico pela sombra (AUMONT, 2014, p. 299). Assim, a sombra é 
o elemento principal da mise-en-scène expressionista, e o recurso mais explorado por este movimento cinematográfico (AUMONT,2014, p. 92).

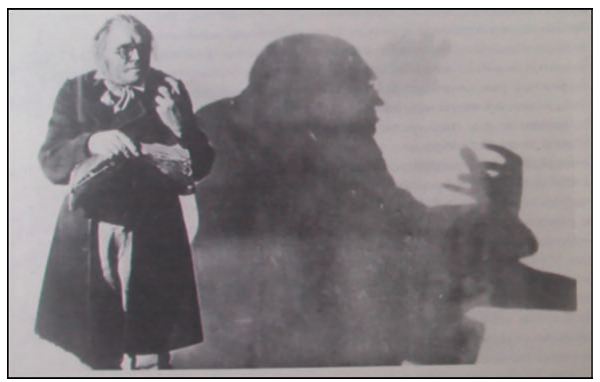

Figura 7 - Fotograma do filme O Gabinete do Dr. Caligari, 1919. Fonte: O Gabinete do Dr. Caligari,1919, dirigido por Robert Wiene. Alemanha (apud STOICHITA, 1999, p. 155).

Segundo Stoichita, a sombra de Caligari é uma "exteriorização do interior do personagem", uma imagem da cor das trevas, que transluz o que o personagem é (STOICHITA, 1999). Otto Rank aponta que em vários contos e lendas o tamanho da sombra se relaciona com a força do personagem, a qual cresce ou diminui de acordo com o comprimento de sua sombra (RANK, 2014, p. 89). Assim, esse elemento narrativo e estilístico expressa o poder demoníaco do protagonista que, por meio da hipnose, induz um homem que não tem consciência do que faz a cometer vários assassinatos, da mesma forma que o diabo se impõe às almas dos condenados ao inferno e de maneira similar à forma como o Führer usava seu carisma contra o povo alemão. Kracauer, com efeito, sustenta que Hitler seria o primeiro a praticar, na esfera política, o domínio da alma em grande escala (KRACAUER, 1985, p. 73). Por conseguinte, a sombra que o malvado Caligari projeta é uma força demoníaca que ousa desafiar Deus.

Por outro lado, no filme Nosferatu, a sombra grotesca que o vampiro projeta (figura 8) é o próprio monstro. Nosferatu não dispõe de silhueta, pois, como recorda Stoichita, "segundo uma antiga tradição os vampiros carecem de sombra" (1999, p. 157); mas ele próprio é a sombra que paira sobre Hutter. Esse ente maligno, assim como o diabo $^{9}$, não possui uma sombra, mas ataca suas vítimas, utilizando artifícios sobrenaturais. Ressaltamos que para o ocultista Albin Grau, diretor artístico e produtor do filme, as sombras fazem visíveis as forças invisíveis e escuras, "o outro lado"10.

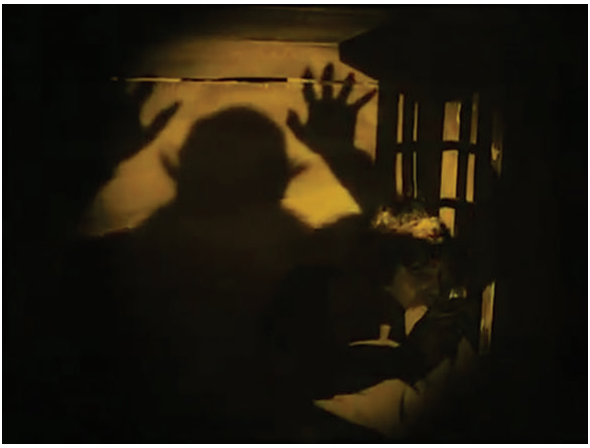

Figura 8 - Fotograma do filme Nosferatu (Nosferatu, Eine Symphonie des Grauens, 1922), dirigido por F. W. Murnau. Fonte: Filme Nosferatu (Nosferatu, Eine Symphonie des Grauens, 1922), dirigido por F. W. Murnau

\section{Da camada de sombra (Catch preto) ao corpo sonoro}

Aquilo que nos causa medo oculta-se na sombra; a mesma manifestação é representada no filme Nosferatu de diferentes formas: sombras projetadas, inerentes, fundos negros e catches pretos. As sombras projetadas e inerentes e os fundos negros se mantêm atuais no cinema de terror contemporâneo, porém os catches pretos, que não têm uma referência naturalista, desapareceram, gradualmente, do cinema sonoro.

Contudo, no cinema de Murnau, esses elementos estilísticos contribuem para a criação da atmosfera assustadora. Para os pesquisadores Michel Bouvier e Jean-Louis Leutrat, a camada de sombra que cobre os planos dos personagens que olham para fora de campo e das paisagens aparece "como significante (na imagem) de 'uma ameaça indescritível' ou 'um pressentimento obsessivo'"11 (apud AUMONT, 1990, p. 197).

As camadas de sombra criam uma atmosfera sinistra em cenas que expressam uma aparente tranquilidade, a sombra prenuncia que a qualquer momento algo estranho pode acontecer. Dessa forma o catch preto é um elemento estilístico que cria um clima de tensão, pois sugere que o monstro que se oculta na sombra dos cantos do plano emergirá a qualquer momento.

Para exemplificar o estilo de Murnau analisaremos duas cenas nas quais percebemos o valor dramático das camadas de sombra. Na primeira, Hutter anda pela parte exterior do castelo de Nosferatu à luz do dia, de maneira descontraída, e se detém para olhar a paisagem, enquanto escreve uma carta para sua amada Ellen (figura 9). Nessa cena, a mise-en-scène expressa uma aparente tranquilidade; no entanto uma fina camada de sombra bordeia o plano criando uma atmosfera estranha. 


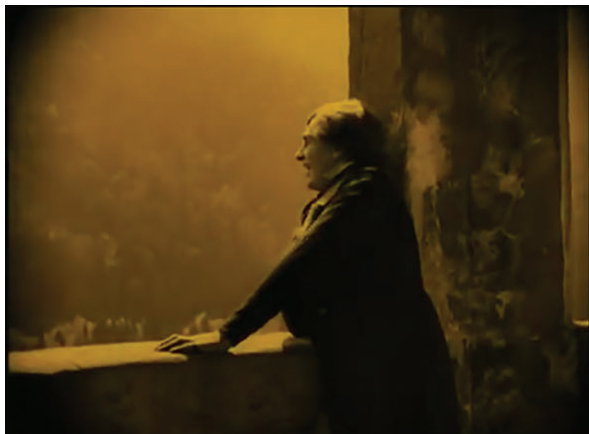

Figura 9 - Fotograma do filme Nosferatu (Nosferatu, Eine Symphonie des Grauens, 1922), dirigido por F. W. Murnau. Fonte: Filme Nosferatu (Nosferatu, Eine Symphonie des Grauens, 1922), dirigido por F. W. Murnau.

Por outro lado, em outra cena, Hutter, após descobrir a verdadeira identidade do seu anfitrião, assombrado, observa o vampiro abandonar o castelo a uma velocidade antinatural. Entretanto, uma densa camada de sombra circular rodeia esse plano (figura 10). Dessa forma, as camadas de sombra contribuem para criar uma atmosfera sinistra na mise-en-scène e aumentar a tensão dramática.

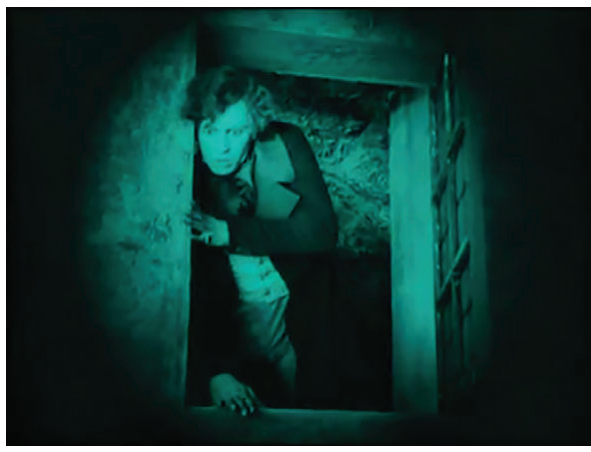

Figura 10 - Fotograma do filme Nosferatu (Nosferatu, Eine Symphonie des Grauens, 1922), dirigido por F. W. Murnau. Fonte: Filme Nosferatu (Nosferatu, Eine Symphonie des Grauens, 1922), dirigido por F. W. Murnau.

$\mathrm{Na}$ cena seguinte, que inicia com uma abertura da íris que deixa uma camada de sombra ao redor do plano, Ellen, vestida de negro, espera frente ao mar o retorno do marido (figura 11 ) $^{12}$, as camadas de sombras e os elementos fílmicos estão contaminados pela presença do vampiro. Nesses elementos estilísticos se encontra uma "ameaça iminente, porém oculta” (BOUVIER \& LEUTRAT apud AUMONT, 1990, p. 198). Assim, "Ellen se situa na fronteira entre as ondas representantes da ameaça mortal, e a terra da qual surgirão seus amigos"13 (BOUVIER \& LEUTRAT apud AUMONT, 1990, p. 195).

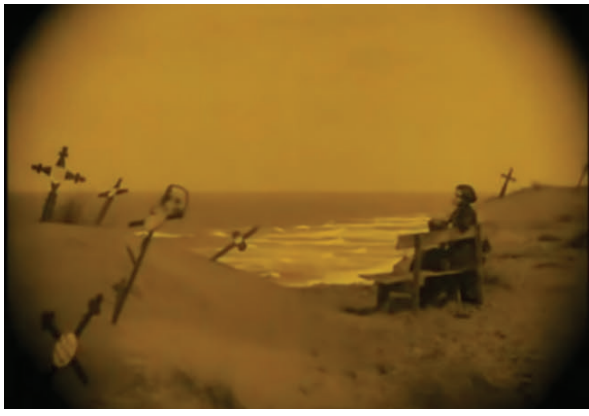

Figura 11 - Fotograma do filme Nosferatu (Nosferatu, Eine Symphonie des Grauens, 1922), dirigido por F. W. Murnau. Fonte: Filme Nosferatu (Nosferatu, Eine Symphonie des Grauens, 1922), dirigido por F. W. Murnau.

Essa ameaça iminente encontra-se em vários planos, como, por exemplo: na abertura da íris, no plano do veleiro Empusa ${ }^{14}$ que transporta o vampiro e seus caixões rumo a Wisborg, no contraste entre a luz e a sombra que extrai das trevas os ratos (figura 12) e na camada de sombra ao redor do plano do marujo aterrorizado pelo vampiro (figura 13), entre outros.

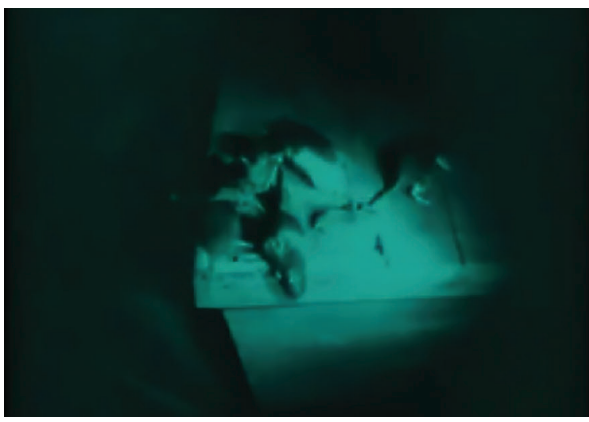

Figura 12 - Fotograma do filme Nosferatu (Nosferatu, Eine Symphonie des Grauens, 1922), dirigido por F. W. Murnau. Fonte: Filme Nosferatu (Nosferatu, Eine Symphonie des Grauens, 1922), dirigido por F. W. Murnau

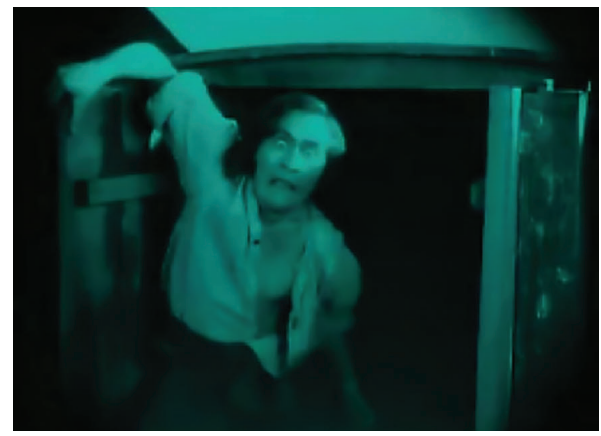

Figura 13 - Fotograma do filme Nosferatu (Nosferatu, Eine Symphonie des Grauens, 1922), dirigido por F. W. Murnau Fonte: Filme Nosferatu (Nosferatu, Eine Symphonie des Grauens, 1922), dirigido por F. W. Murnau 
Esses elementos fílmicos sinalizam a aparição do monstro, ainda oculto na escuridão. Bouvier e Leutrat observam que "as camadas de sombra ao redor dos planos têm algo de inquietante, como se nelas se refugiasse o marginal" (apud AUMONT,1990, p. 197). ${ }^{15}$ Dessa forma as camadas de sombra evocam um medo natural à chegada desse estranho ser à cidade. Como aponta Marie-Louise Von Franz, em tempos antigos e nas sociedades primitivas "o estranho estava errado e era perigoso, trazendo consigo a atmosfera de doença, do homicídio, da morte e dos distúrbios nas relações humanas..." (VON FRANZ, 1985, p. 200)

Para anunciar a chegada do vampiro, a montagem cria uma conexão causal com planos com camadas de sombras ao seu redor, tendo em comum o vento, o qual faz as ondas do mar agitarem-se violentamente e rebentarem com força na praia (figura 14). Esse vento de mau agouro no expressionismo cumpre um "papel dramático" sempre reservado aos elementos da natureza (EISNER, 2002, p. 109). De fato, "em muitos sistemas mitológicos o ar é considerado como o lugar por onde vagueiam os fantasmas e os espíritos, como Wotan e seu exército de fantasmas de morte voando pelo ar, especialmente em noites de tempestades, caçando com os mortos" (VON FRANZ, 1985, p. 55). Também, Nosferatu, assim como o demônio Pazuzu da antiga Mesopotâmia, se metamorfoseia no vento e traz as doenças e os maus espíritos (NICHOLS, 1994, p. 179). No Talmude, esses demônios que acompanharam Satã quando foi expulso do céu inspiravam "os pensamentos maléficos que entram na mente e no coração da humanidade; no Novo Testamento eles levam ao pecado, trazem doenças, e aflições mentais" (SANFORD,1988, p. 144).

O movimento das ondas (figura 14) se une em continuidade gráfica com o das cortinas no quarto da esposa de Harding. Ela acorda e caminha até o quarto de Ellen que se encontra em estado de transe, com os braços estendidos na sacada, ambiente no qual vemos folhas que balançam com o vento (Figura 15). Ellen olha para fora do quadro e diz: "Preciso ir com ele, ele está vindo".

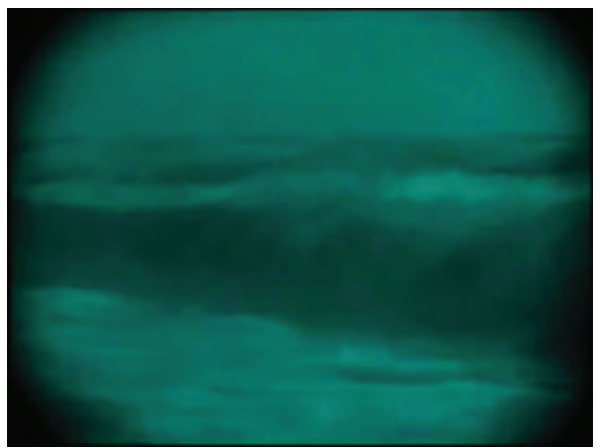

Figura 14 - Fotogramas do filme Nosferatu (Nosferatu, Eine Symphonie des Grauens, 1922), dirigido por F. W. Murnau. Fonte: Filme Nosferatu (Nosferatu, Eine Symphonie des Grauens, 1922), dirigido por F. W. Murnau

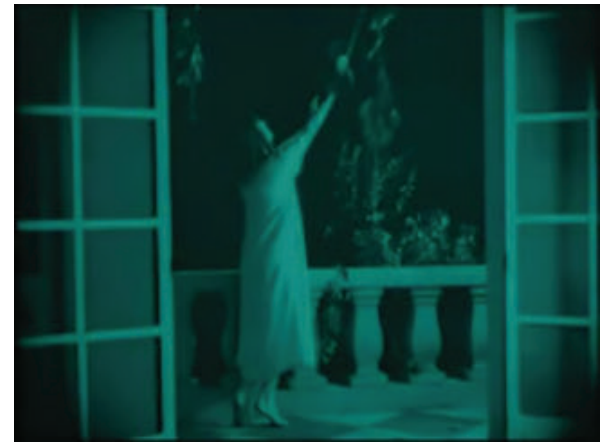

Figura 15 - Fotogramas do filme Nosferatu (Nosferatu, Eine Symphonie des Grauens, 1922), dirigido por F. W. Murnau. Fonte: Filme Nosferatu (Nosferatu, Eine Symphonie des Grauens, 1922), dirigido por F. W. Murnau.

Murnau usa as camadas de sombra nesses planos para sugerir a ameaça do vampiro. Essa sequência é acompanhada pelo som de uma música orquestral que aumenta a tensão dramática, mas não substitui o som diegético ${ }^{16}$ do vento, evocado pelo movimento dos elementos fílmicos na mise-en-scène.

$\mathrm{Na}$ composição audiovisual do cinema contemporâneo, o som do vento, nessa sequência, provavelmente sugeriria a iminente e ameaçadora chegada do vampiro, sem precisar do recurso estilístico das camadas de sombra (catches pretos), as quais foram abandonadas na transição do cinema mudo ao cinema sonoro. A partir daí, o monstro não precisa se esconder na sombra, mas se expressa nos elementos sonoros do filme ou por meio de um som acusmático ${ }^{17}$, como, por exemplo, em Tubarão (Jaws, 1975, dir. Steven Spielberg), no qual o c orpo sonoro do animal cria atmosferas sinistras, substituindo as camadas de sombra.

\section{O Anjo azul}

Na transição do cinema mudo ao cinema sonoro, o filme $O$ anjo azul, baseado no romance de Heinrich Mann Professor Unrath, articula sombras e sons sincrônicos e assincrônicos para representar a degradação do professor Inmanuel Rath (Emil Jannings). Numa mise-en-scène de ruas tortuosas, casas de penhor com telhados expressionistas, oblíquos, alongados de autoria do cenógrafo alemão Otto Hunte (EISNER, 2002, p. 220), a apresentação da sensual Lola Lola (Marlene Dietrich) no cabaré $O$ anjo azul chama a atenção dos alunos do professor, que preferem ir ao espetáculo da artista que às aulas de Rath. Para dar uma lição aos estudantes, o professor ingressa nesse antro com a intenção de acertar as contas com Lola Lola, porém sucumbe aos encantos dela, até o ponto de se casar com a dançarina e seguila, largando suas aulas. Ao terminar seus ingressos o professor se torna, praticamente, um escravo de Lola, visto que a mulher o obriga a vender insinuantes fotos suas aos fregueses. Porém o pior acontece quando 
o espetáculo de Lola volta ao cabaré $O$ anjo azul e ela anuncia como parte do show a apresentação do envelhecido professor Rath disfarçado de palhaço. Ele é forçado a fazer parte do espetáculo de um mágico que o humilha na frente do público da sua cidade.

Nessa cena, Rath se apresenta ao público (figura 16) com o rosto pintado de palhaço e usando o sobretudo e o chapéu que vestia quando era professor, ele é uma caricatura do homem que algum dia foi. O mago começa a fazer vários truques, como tirar pombas do chapéu do professor e ovos do seu nariz, porém ousa até mesmo quebrar os ovos na testa do infeliz. Nesse transe repugnante, o algoz ainda exige que o protagonista cante como um galo. Nesse momento, atrás do palco, Lola beija um amante, traindo descaradamente a seu marido que observa do palco esta ação. Assim, nessa insuportável situação, dominado pela loucura, "Rath lança um grito desgarrador que gela o sangue dos assistentes, um quiquiriqui animal, não o canto solicitado, farsesco, senão um uivo nos limites do humano"18 (SANCHEZBIOSCA, 190, p. 435).

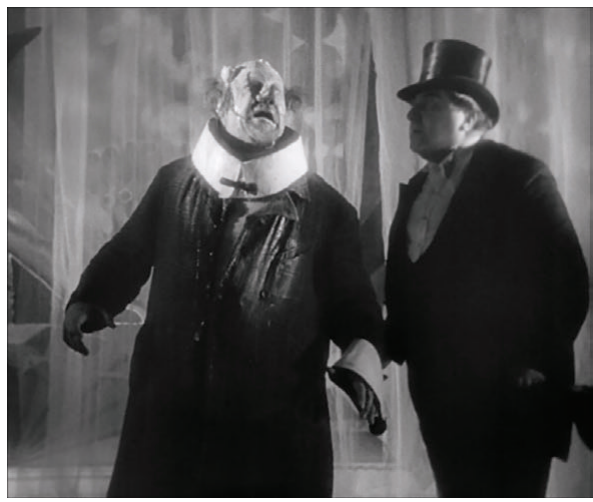

Figura 16 - Fotograma do filme O anjo azul (Der blaue Engel, $1930)$ de Josef von Sternberg. Fonte: Filme O anjo azul (Der blaue Engel, 1930) de Josef von Sternberg.

No degradante espetáculo imposto ao professor, ovos e canto compõem uma experiência dolorosa. O professor se mexe pelo cenário até ser coberto por uma sombra cinzelada por uma contraluz (figura 17). Destarte, tanto os elementos fílmicos como sonoros expressam desespero: o verdadeiro passe de mágica foi desumanizar o personagem até que ele se transformasse num animal desesperado, que expressa sua dor por meio de um grito desumano que entra na esfera do sinistro. O elemento sonoro, a sombra e os demais elementos fílmicos criam uma cena inesquecível que chega ao mais profundo da alma.

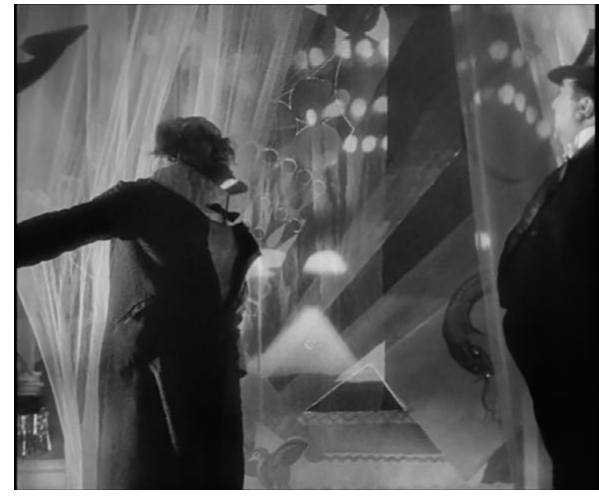

Figura 17 - Fotograma do filme O anjo azul (Der blaue Engel, 1930) de Josef von Sternberg. Fonte: Filme O anjo azul (Der blaue Engel, 1930) de Josef von Sternberg.

Em suma, no início do cinema sonoro, quando a maioria dos filmes falados parecia desajeitada ao ser comparada com as deslumbrantes invenções do cinema mudo tardio (BORDWELL, 2013, p. 56), esta obra recupera a beleza plástica destes filmes e, além disso, confere expressividade aos elementos sonoros, à iluminação e ao silêncio, entre outros recursos, ampliando o efeito dramático das cenas.

Do mesmo modo, elementos sonoros e sombras têm um papel fundamental no filme $M-O$ vampiro de Düsseldorf, de Fritz Lang. Nessa obra, baseada em fatos reais, o protagonista Hans Beckert (Peter Lorre), um burguês de aparência inofensiva algo infantil e afeminada, é na realidade um maníaco assassino de crianças, o qual é perseguido tanto pela polícia como pelos delinquentes da cidade. Esse último grupo captura-o e o julga num tribunal improvisado, no qual é condenado à morte pelos seus atos execráveis; porém, no último momento, a polícia resgata Beckert que, finalmente, é julgado e condenado pelo Estado.

$\mathrm{Na}$ cena que apresenta o assassino, a menina Elsie Beckmann caminha pela calçada, brincando com uma bola que ela quica no chão e depois contra um poste que está fora de campo. A câmara segue esse movimento e enquadra a bola batendo num cartaz com a seguinte informação:

10.000 MARCOS DE RECOMPENSA. QUEM É O ASSASSINO? Desde 11 de junho o pequeno Klaus Klawitzky e sua irmã Klara desapareceram. As evidências nos levam a acreditar que as crianças foram vítimas do mesmo tipo de crime do último cometido contra as irmãs Doering ${ }^{19}$ (1931).

Nesse momento a sombra dura do assassino se projeta no cartaz (figura 18). Dessa forma a primeira aparição do psicopata se dá por meio de um duplo representado nessa sombra. Segundo SánchezBiosca, essa silhueta é uma metáfora do duplo, porquanto as ações desse indivíduo escapam de sua consciência, visto que elas se realizam num terreno inacessível a seu controle e, portanto, falam de seu desdobramento (SÁNCHEZ-BIOSCA, 1990, p. 436). 
Assim, as forças escuras que transformam esse indivíduo num monstro que, em estado delirante comete crimes execráveis, se condensam naquela silhueta do perfil do protagonista que evoca as skiagraphias lavaterianas.

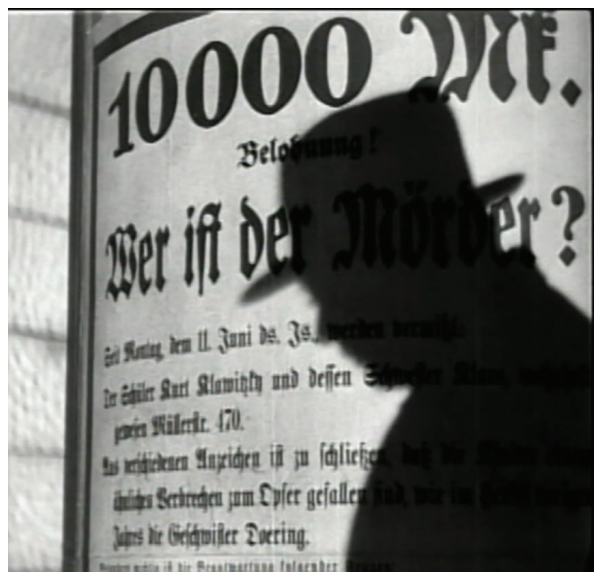

Figura 18 - Fotograma de $\mathrm{M}$ - o vampiro de Düsseldorf $(M-$ Eine Stadt sucht einen Mörder, 1931) dirigido por Fritz Lang. Fonte: $\mathrm{M}$ - o vampiro de Düsseldorf ( $M$ - Eine Stadt sucht einen Mörder, 1931) dirigido por Fritz Lang.

Ainda nesse plano escuta-se a voz "neutra e simulada" (SÁNCHEZ-BIOSCA, 1990, p. 436) do psicopata que diz para a menina: "Que linda bola!". A sombra do assassino se inclina um pouco mais, invadindo o espaço do cartaz. Ele pergunta como se chama a menina, ao que a pequena responde (voz em off) "Elsie Beckmann". Dessa forma, os corpos sonoros dos personagens ocupam essa cena junto com os elementos fílmicos: a bola, que representa a presença metonímica de Elsie, e a sombra, que é a metáfora do duplo demoníaco de Beckert (SÁNCHEZBIOSCA, 1990).

Beckert compra para Elsie, de um vendedor cego, um balão, entretanto assobia ${ }^{20}$ uma ária de Peer Gynt, de Edvard Grieg (NAZARIO, 1999, p. 242). A menina agradece o presente e sai do plano acompanhando o assassino. O assobio que expressa o nível de excitação do monstro continua audível na perspectiva sonora; dessa forma, neste filme o corpo sonoro do protagonista tem uma função análoga à sombra que ele projeta, visto que Beckert é introduzido na história pela voz, o assobio e pela sombra antes de ser visualizado pelo público. Acompanhando o silvo que emite o assassino, o plano mostra os elementos fílmicos dessa cena, nos quais se destacam o velho vendedor cego e os balões que têm as formas de criança (figura 19). Metáfora da fragilidade das vítimas.

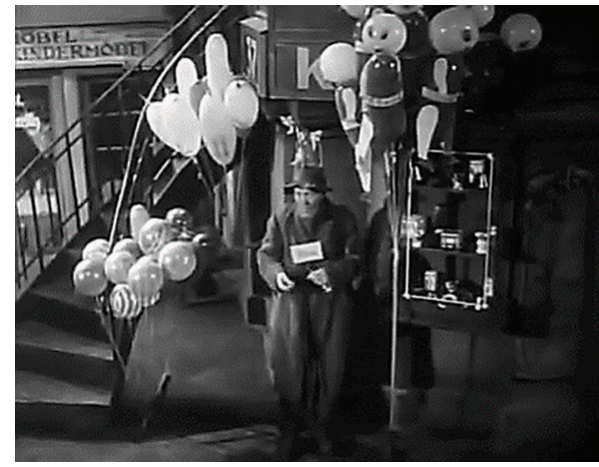

Figura 19 - Fotograma de $\mathrm{M}$ - o vampiro de Düsseldorf ( $M$ Eine Stadt sucht einen Mörder, 1931) dirigido por Fritz Lang. Fonte: $\mathrm{M}$ - o vampiro de Düsseldorf ( $M$ - Eine Stadt sucht einen Mörder, 1931) dirigido por Fritz Lang.

Esse ancião, que reconhece o assobio do assassino, informa a um dos criminosos a localização de Beckert. Este homem escreve com giz a letra "M" de assassino (mörder) na palma da mão e marca o infanticida nas costas, sem que este perceba que foi descoberto e que os delinquentes seguem esse sinal. $\mathrm{O}$ assassino finalmente é capturado e levado a um prédio em ruínas. Nesse lugar, dois criminosos o tiram de um espaço coberto de trevas (figura 20) que evoca a sombra da qual emergem os personagens expressionistas (figuras 2 e 3). E o inferno, um lugar escuro e subterrâneo.

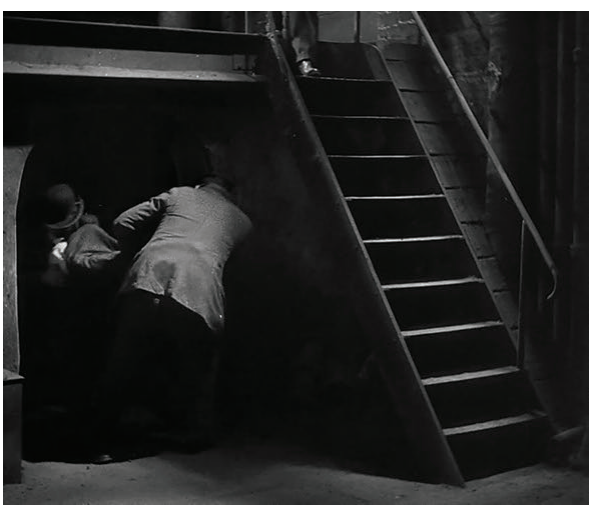

Figura 20 - Fotograma de $\mathrm{M}$ - o vampiro de Düsseldorf ( $M$ Eine Stadt sucht einen Mörder, 1931) dirigido por Fritz Lang. Fonte: $\mathrm{M}$ - o vampiro de Düsseldorf ( $M$ - Eine Stadt sucht einen Mörder, 1931) dirigido por Fritz Lang.

Ele é levado, contra a vontade, a um estranho tribunal formado pelos delinquentes, os quais the concedem a defesa de um advogado. Beckert exige ser entregue à polícia, porém a corte de antissociais rejeita essa ideia, visto que eles temem que o Estado o liberte, alegando que é um doente mental que não tem controle sobre seus atos. Desesperado, o infanticida se justifica dizendo: 
Quem são vocês? Criminosos? Todos criminosos? Arrombam cofres, assaltam casas, batem carteiras, mas poderiam ter sido outras coisas se alguém Ihes tivessem ensinado a trabalhar e se vocês não fossem um bando de bastardos preguiçosos. Mas... não posso ajudar a mim mesmo! Não tenho controle sobre isto. Este coisa diabólica [sic] entrou em mim, o fogo, as vozes, o tormento! Está lá o tempo todo, controlando os meus desejos pelas ruas seguindome, silenciosamente, mas não posso parar. Isto me possui $^{21}$ (1931).

Com o rosto cinzelado por sombras duras e as mãos com os dedos dobrados como se fossem garras (figura 21), ele diz que tem que obedecer a comandos internos que não domina e que após cometer os assassinatos não se lembra de nada. Alega que é forçado a matar, que não quer fazer isso, mas que não pode ir contra o poder sobre-humano que o submete, o qual se manifesta em vozes insuportáveis que ele não consegue parar de escutar. Poderíamos dizer que esse homem lamenta sua tormentosa existência sob o jugo da psicose. Essa patologia desde sempre tem estado associada ao demônio, como salienta o psicólogo existencialista Rollo May:

a moderna palavra demônio deriva da noção grega clássica do daimon, que oferece a base para o seu modelo mitológico do daemônico ${ }^{22}$ : "O daemônico é qualquer função natural que tenha o poder de dominar toda a pessoa. Por exemplo, sexo e erotismo, raiva e fúria ou o desejo de poder. $O$ daemônico tanto pode ser criativo como destrutivo, e geralmente é ambos. Quando essa força se descontrola e um elemento usurpa o controle sobre a personalidade como um todo, temos a 'possessão pelo daimon', o nome tradicional para a psicose ao longo da História (apud DIAMOND,1994, p. 205).

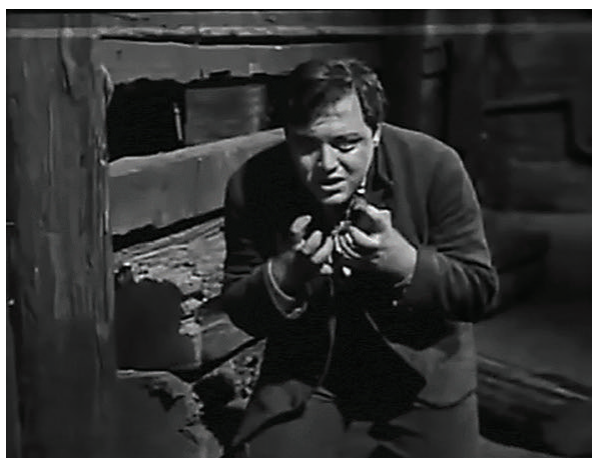

Figura 21 - Fotograma de $\mathrm{M}$ - o vampiro de Düsseldorf ( $M$ Eine Stadt sucht einen Mörder, 1931) dirigido por Fritz Lang. Fonte: Filme $\mathrm{M}$ - o vampiro de Düsseldorf ( $M$ - Eine Stadt sucht einen Mörder, 1931) dirigido por Fritz Lang.

Igualmente, no Novo Testamento, a loucura está associada ao mal, uma vez que Satã, assistido por um bando de demônios, provoca aflições mentais aos indefesos humanos, flagelados com essa tortura. Como aponta Sanford, ao se referir ao evangelho de Lucas (Lc 8 ,28-34), "Os vários demônios que se apossaram do país dos gerasenos suplicaram a Jesus que não os mandasse para o abismo, e ele os mandou para uma vara de porcos (SANFORD 1988, p. 50).

Finalmente, podemos inferir que as características demoníacas do protagonista de $M$ se acentuam no momento em que ele é substituído tanto pela sombra que projeta (figura 18) como pelo corpo sonoro que emite, o qual é constituído pela voz estridente de Beckert, e pelo silvo que se associa a esse personagem sinistro. Esses elementos fílmicos e sonoros expressam instintos ingovernáveis, atiçados por poderes ocultos atribuídos ao demônio, que o coagem e o obrigam a matar.

Depois de escutar a confissão do maníaco, o chefe dos delinquentes dá o veredicto, apoiado pela maioria, de que "alguém que admite sua compulsão para assassinar deve ser extinto como um incêndio. Este homem tem que desaparecer". O grupo de criminosos age como algumas tribos primitivas que, ao descobrir o demoníaco num indivíduo, o eliminam numa execução ritual.

O primitivo diz que se um ser humano age como se fosse divino, então deve sofrer o destino de um deus e da mesma forma que um deus, deve ser enforcado, morto, esquartejado, e assim por diante. Não se pode viver numa sociedade humana e se comportar como um ser divino que pode matar ad libitum (VON FRANZ, 1985, p. 51).

Antes, porém, de ele ser executado pelos criminosos, o advogado defende o cliente, alegando que ele não tem controle sobre si mesmo e que deve ser internado num manicômio. Os delinquentes rejeitam a proposta porque temem que Beckert um dia receba alta e, prisioneiro da compulsão, cometa mais crimes horrendos. Na hora em que a turba descontrolada pretende fazer justiça com suas próprias mãos, a polícia chega e prende o assassino, o qual finalmente será julgado pelo Estado, num final ambíguo que não explica o tipo de punição que o psicopata irá receber.

\section{Considerações Finais}

A sombra é o elemento mais importante da miseen-scène do cinema expressionista, uma vez que dela emergem personagens diabólicos. Ao ser distorcida e ampliada, ela representa o poder maléfico desses monstros sobre suas vítimas. Ela também os substitui na mise-en-scène, sugerindo que os personagens se encontram fora de campo, e no filme Nosferatu ela é o próprio vampiro que ataca suas vítimas. Esse ente maligno se oculta nas sombras que contornam os planos (catches pretos) de todas as cenas da obra.

Nas criações de influência expressionista da transição do cinema mudo ao cinema sonoro, como $O$ anjo azul e $M$ - o vampiro de Düsseldorf, as sombras e os elementos sonoros são usados de maneira análoga na criação de cenas que expressam as emoções dos protagonistas. Corpos sonoros, assim como sombras, cumprem a função de substituir os personagens. Também o som emitido pelos personagens e as 
sombras que os cinzelam representam situações dramáticas nas quais a voz dos protagonistas expressa suas emoções. Dessa forma a sombra e o som tornam-se elementos narrativos e estilísticos que se complementam na criação de personagens complexos.

No Expressionismo alemão, as sombras conformaram atmosferas aterrorizantes de conotações negativas numa mise-en-escène de silhuetas distorcidas e ampliadas de horríveis personagens, catches pretos que contornam os planos criando atmosferas sinistras e sombras como fossas pretas das quais emergem figuras demoníacas. Na transição do chamado cinema mudo ao sonoro, realizadores influenciados pelo expressionismo criaram os corpos sonoros dos personagens, de forma a cumprir funções análogas às da sombra. Esses fatores acústicos substituem seres sinistros que se encontram fora do enquadramento da tela e evocam, assim como a sombra, o medo ao desconhecido. Elementos estilísticos desse tipo têm sido explorados no cinema de terror contemporâneo, como, por exemplo, no filme Atividade Paranormal (Paranormal Activity, USA, 2007), dirigido por Oren Peli; no qual os elementos sonoros constituem o corpo sonoro de uma entidade demoníaca que se encontra escondida na sombra.

\section{Notas Finais}

${ }^{1}$ Doutor (2017) e Mestre em Artes (2007) pela Universidade Federal de Minas Gerais, orientado pelo Prof. Doutor Luiz Nazario. Roteirista pela Escola Internacional de Cinema e Televisão de Cuba (2003), Especialista em Projetos Cinematográficos pela Valencian International University (Espanha, 2010).

${ }^{2}$ Influenciado pela obra de Goya, Van Gogh, Nolde, Klee, Munch, Kokoschka e Kubin, entre outros, assim como pelo teatro de Max Reinhardt (GUBERN, 2000, p. 137).

${ }^{3} \mathrm{Na}$ tradução ao espanhol de Irene Agoff: "Hemos visto cómo opera el expresionismo con las tinieblas y la luz, el fondo negro opaco y el principio luminoso: las dos potencias se acoplan, se abrazan como luchadores y dan al espacio una intensa profundidad, una perspectiva acusada y deformada que se va a llenar de sombras."

${ }^{4} \mathrm{Na}$ versão ao espanhol de Víctor Goldstein e Marina Malfe: "Las diversas definiciones dadas al expresionismo cinematográfico, inspiradas en definiciones pictóricas y teatrales, son generalmente bastante arbitrarias, pero confluyen todas en algunos elementos: el tratamiento de la imagen como 'grabado' (fuerte contraste del blanco y negro); los decorados muy gráficos, donde predominan los planos inclinados; el juego de 'rodeo' de los actores; el tema de la rebelión contra la autoridad."

5 Os elementos narrativos levam o público a deduzir causas e efeitos e a construir uma história total. Os elementos estilísticos definem a atmosfera do filme, sua mise-en-scène . Cada parte está vinculada com a outra, e na mente do público é por meio de ambas que o filme adquire sentido (BORDWELL \& THOMPSON, 1993, p. 42).

${ }^{6} \mathrm{Na}$ tradução ao espanhol de Mariel Manrique / Hernán Maturet: Cuando Cesare se desliza a lo largo del muro para visitar a la muchacha, uno tiene la sensación de ver un charco negro, un cuerpo que es puro derrame del negro, que porta consigo la noche que lo circunda y también la pintura del decorado.

${ }^{7} \mathrm{Na}$ tradução ao espanhol de Yolanda Fontal Rueda: "Las formas están distorsionadas y exageradas, de forma poco realista, con fines expresivos. Los actores llevan a menudo mucho maquillaje y se mueven de forma espasmódica o lenta y sinuosa. $Y$ lo que es más importante, todos estos elementos de la puesta en escena interactúan gráficamente para crear una composición global. Los personajes no existen simplemente dentro de un decorado, sino que más bien forman elementos visuales en el interior del decorado."

${ }^{8} \mathrm{En}$ el cine, la sombra de los seres puede transformarse en personaje [...] casi siempre en el registro de lo fantástico o la proyección psíquica (la sombra de los asesinos

9 O diabo "segundo crenças russas, [...] assim como demônios malignos, [...] não têm sombra e por isso é tão ávido das sombras dos humanos (RANK, 2014, p. 52).

${ }_{10}$ Documental: El Lenguaje de las Sombras - Friedrich Wilhelm Murnau y sus películas: Años de juventud y "Nosferatu". De Luciano Berriatua. In https://www.youtube.com/ watch? $v=\mid x j J C l B u s f k \& t=2829 s$. Acesso em 13 de nov. 2017.

${ }^{11} \mathrm{Na}$ tradução ao espanhol de Carlos Losilla: "una amenaza indescriptible, o de un presentimiento obsesivo."

${ }^{12}$ Bouvier e Leutrat comparam esse plano com as pinturas de Caspar David Friedrich, Mujer al Borde del mar e Cementerio de convento.

${ }^{13} \mathrm{Na}$ tradução ao espanhol de Carlos Losilla: "Ellen se sitúa en la frontera entre las olas representantes de la amenaza mortal, y la tierra de la que surgirán sus amigos."

${ }^{14} \mathrm{~s}$. f. II (mit.) espectro horrendo que Hécate mostrava aos condenados no inferno. (...) F. gr. Empousa. Disponívelem:http://www.aulete.com.br/Empusa\#ixzz3pISUrt|3. Acesso em 13 de nov. 2017.

${ }^{15} \mathrm{Na}$ tradução ao espanhol de Carlos Losilla: "El cache tiene así algo de inquietante, como si en sus sombras se refugiara lo marginal".

${ }^{16}$ Em uma rígida convenção narrativa estabelecida desde os primórdios da arte audiovisual, os ruídos e os diálogos têm um caráter mais realista - eles representam a realidade de forma mais objetiva. No campo auditivo correspondem aos sons emitidos por aqueles elementos que vemos na tela ou que estão em torno dela. Chamamos esses sons de diegéticos, pois pertencem ao mundo ficcional habitado pelos personagens. (CARREIRO, 2018, p. 22).

${ }^{17}$ Acusmático é uma antiga palavra de origem grega que significa "que se escuta sem ver a causa originária do som", "que faz ouvir sons sem a visão de suas causas" (CHION, 1993, p. 74).

${ }^{18}$ No original: Rath [...] lanza un grito desgarrador que hiela la sangre de los asistentes, un kikiriki animal, no el canto solicitado, farsesco, sino un aullido en los límites de lo humano.

${ }^{19} \mathrm{M}$ - o vampiro de Düsseldorf ( $M$ - Eine Stadt sucht einen Mörder, 1931) de Fritz Lang

${ }^{20}$ É bastante comum, nos filmes, que certos personagens com aura maléfica, importante ou impressionante sejam quase introduzidos pelo som antes de serem vistos na tela (CHION, 1993, p. 75).

${ }^{21}$ Filme $\mathrm{M}$ - o vampiro de Düsseldorf ( $M$ - Eine Stadt sucht einen Mörder, 1931) dirigido por Fritz Lang

${ }^{22}$ May concebe o daemônico "como uma força primordial da natureza, essencialmente indiferenciada e impessoal. Pois, para os gregos primitivos, o daimon podia ser mau ou criativo, fonte da destruição ou da orientação espiritual [...]. A palavra daimon foi ocasionalmente utilizada por Platão como sinônimo de theos (deus); e o poderoso Eros também era um daimon" (1994, p. 205).

\section{Referências Bibliograficas}

Aumont, Jacques; Marie, Michel. 1990. Análisis del film. Tradução de Carlos Losilla. Barcelona: Paidós.

Aumont, Jacques. 2014. Materia de imágenes, redux. Traducción Mariel Manrique and Hernán Marturet. Cantabria: Shangrila.

Aumont, Jacques y Michel Marie. 2015. Diccionario teórico y crítico del cine. Traducción Víctor Goldstein y Marina Malfe. Buenos Aires: La Marca editora. 
Bordwell, David. Sobre a história do Estilo Cinematográfico. Tradução de Luís Carlos Borges. Campinas, SP: Unicamp, 2013.

Bordwell, David and Kristin Thompson. 1993. El arte cinematográfico. Traducción Yolanda Fontal Rueda. Barcelona: Paidós.

CARREIRO, Rodrigo. O som do filme: uma introdução. 2018. Curitiba: Editora UFPR.

Castelli, Enrico. 2007. Lo demoníaco en el arte: su significado filosofico. Tradução de María Condor. Madrid: Siruela.

Chion, Michel. 1993. La audiovisión. Tradução de Antonio López Ruiz. Barcelona: Paidós.

Deleuze, Gilles. 1984. La imagen movimiento. Traducción de Irene Agoff. Barcelona: Paidós.

DIAMOND, Stephen A. A remissão dos nossos diabos e demônios. 1994. In: ZWEIG, Connie; ABRAMS, Jeremiah (org.). Ao encontro da sombra: o potencial oculto do lado escuro da natureza humana. Tradução de Merle Scoss. São Paulo: Cultrix.

Eisner, Lotte. 2002. A Tela Demoníaca: as influências de Max Reinhardt e do Expressionismo. Tradução Lúcia Nagib. Rio de Janeiro: Paz e Terra.

Gombrich, Ernst Hans. 1995. Historia del arte. Traducción de Rafael Santos Torroella. Hong Kong: Diana.

Gubern, Román. 2000. Historia del Cine. Barcelona: Editorial Lumen.

Jullier, Laurent. 2007.El sonido en el cine. Tradução de Antonio Francisco Rodríguez. Barcelona: Paidós

Kracauer, Siegfried. 1985. De Caligari a Hitler: una historia psicológica del cine alemán. Traducción de Héctor Grossi. Buenos Aires: Paidós.

Lira, Bertrand. 2008. Luz e Sombra: Uma interpretação de suas significações imaginárias nas imagens no cinema expressionista alemão e do cinema noir americano. Tese (Doutorado em Ciências Sociais). Rio Grande do Norte, UFRN. https://repositorio.ufrn.br/jspui/ handle/123456789/13678. Acedido em 15 de maio de 2019.

Nazario, Luiz. 1999. As sombras móveis: atualidade do cinema mudo. Belo Horizonte: Editora UFMG.

Nichols, Sallie. 1994. O Diabo no Tarô. In: ZWEIG, Connie; ABRAMS, Jeremiah (org.). Ao encontro da sombra: o potencial oculto do lado escuro da natureza humana. Tradução de Merle Scoss. São Paulo: Cultrix.

Pastoreau, Michel. 2011. Preto: história de uma cor. São Paulo: Senac.

Rank, Otto. 2014.O duplo. Tradução de Ana Maria Lisboa de Mello. Porto Alegre: Dublinense.

ROBALINO, Juan. 2017. A sombra no cinema: análise da carga negativa da sombra. Belo Horizonte: UFMG. Tese (Doutorado em Artes). http://www.bibliotecadigital.ufmg. $\mathrm{br} / \mathrm{dspace} / \mathrm{handle/1843/LOMC-BBYHBT}$. Acedido em 5 de junho de 2019.

Sánchez-Biosca, Vicente. 1990. Sombras de Weimar: contribución a la historia del cine alemán 1918-1933. Madrid: Verdoux.

Sanford, John A. 1988. Mal: o lado sombrio da realidade. Tradução Silvio José Pilon e José Silvério Trevisan. São Paulo: Paulus.

Stoichita, Victor. 1999. Breve historia de la sombra. Traducción Anna María Coderch. Madrid: Siruela.

Von franz, Marie-Louise. 1985. A sombra e o mal nos contos de fada. Tradução de Maria Christina Penteado Kujawski. São Paulo: Paulinas.

Zweig, Connie e Jeremiah Abrams (org.). Ao encontro da sombra: o potencial oculto do lado escuro da natureza humana. Tradução Merle Scoss. São Paulo: Cultrix.

\section{Filmes}

O cantor de jazz (The Jazz Singer) 1927. De Alan Crossland. EUA. https://www.youtube.com/ watch? $v=r q Q n U m K X p B Q$. Acedido em 15 de maio de 2019.

O Gabinete do Dr. Caligari (Das Cabinet des Dr. Caligari) 1919. De Robert Wiene. Alemanha. https://www. youtube.com/watch?v=a4IQbHeznjw. Acedido em 15 de maio de 2019.

Nosferatu (Nosferatu, Eine Symphonie des Grauens) 1922. De F. W. Murnau. Alemanha. https://www.youtube. com/watch? $v=7 v X n U C S p S S Y$. Acedido em 15 de maio de 2019.

O Anjo Azul (Der blaue Engel) 1930. De Josef von Sternberg. Alemanha. https://www.youtube.com/ watch? $\mathrm{v}=\mathrm{LX}$ cxyAs2V68. Acedido em 15 de maio de 2019.

$M$ - O vampiro de Düsseldorf ( $M$ - Eine Stadt sucht einen Mörder) 1931, De Fritz Lang. Alemanha. https://www. youtube.com/watch?v=r9RLbwkVPoA. Acedido em 15 de maio de 2019. 